ISSN 1817-7204(Print)

ISSN 1817-7239(Online)

УДК 519.8:631.5

https://doi.org/10.29235/1817-7204-2018-56-3-321-334

Поступила в редакцию 27.03.2018

Received 27.03.2018

\title{
А.П. Лихацевич
}

Институт мелиоращии, Национальная академия наук Беларуси, Минск, Беларусь

ИСПОЛЬЗОВАНИЕ МАТЕМАТИЧЕСКОГО МОДЕЛИРОВАНИЯ
ДЛЯ ПОВЫШЕНИЯ ДОСТОВЕРНОСТИ ОЦЕНКИ РЕЗУЛЬТАТОВ
ПОЛЕВОГО АГРОНОМИЧЕСКОГО ОПЫТА

Аннотация: Программирование (модеирование) урожая в зоне «рискованного земледелия», к которой относится Беларусь, по данным однофакторного эксперимента, учитывающего только пищевой режим, может привести к недопустимо большим ошибкам в расчетах. Этих ошибок достатьчно просто избежать при повышении факторности агрономического опыта путем использования стандартных метеорологических данных, обработанных с использованием математической модели урожая сельскохозяйственных культур. Предложена и апробирована математическая модель влияния факторов среды на урожай сельскохозяйственных культур. Показано, что с ростом числа учитываемых урожаеформирующих факторов точность моделирования (расчета) урожая возрастает. Продемонстрированы возможности математического моделирования, позволяющего перейти от однофакторного к многофакторному агрономическому исследованию, привлекая при анализе полученных результатов опыта в качестве дополнительной информации метеорологические данные, характеризующие влаго- и теплообеспеченность вегетационного периода. Условия влагообеспеченности можно достаточно точно характеризовать атмосферными осадками, выпадающими в течение вегетации, а теплообеспеченность - максимальными суточными температурами воздуха в этот же период. Включение в анализ дополнительно водного и теплового факторов урожая позволяет не только увеличить факторность полевого опыта, но и на основе предложенной математической модели существенно повысить обоснованность выводов по его результатам.

Ключевые слова: математическое моделирование, полевой агрономический опыт, факторы среды обитания растений, пищевой режим, увлажнение почвы, тепловой режим, урожайность, урожаеформирующие факторы, сельскохозяйственные культуры

Для цитирования: Лихацевич, А.П. Использование математического моделирования для повышения достоверности оценки результатов полевого агрономического опыта / А.П. Лихацевич // Вес. Нац. акад. навук Беларусі. Сер. аграр. навук. - 2018. - Т. 56, №3. - С. 321-334. https://doi.org/10.29235/1817-7204-2018-56-3-321-334

\section{A.P. Lichazevich}

The Institute of Land Reclamation, the National Academy of Sciences of Belarus, Minsk, Belarus

\section{MATHEMATICAL SIMULATION FOR IMPROVEMENT OF RELIABILITY OF EVALUATION OF THE FIELD AGRONOMIC EXPERIMENT RESULTS}

\footnotetext{
Abstract: The programming (simulation) of yield in the area of "risky farming" that Belarus belongs to according to data from a single-factor experiment considering only the food mode, can lead to unacceptably large errors in the calculations. These errors can easily be avoided by increasing the factorality of agronomic experiment by using standard meteorological data processed using mathematical model of crop yields. A mathematical model of environmental factors effect on crop yields is proposed and tested. It is shown that the accuracy of yield simulation (calculation) increases with the growing number of crop-forming factors taken into account. The possibilities of mathematical simulation allowing to switch from one-factor to multifactorial agronomic research are demonstrated, involving meteorological data characterizing the moisture and heat availability of the vegetation period when analyzing the results of the experiment as additional information. The moisture supply conditions can be characterized quite accurately by atmospheric precipitation during the vegetation period, and the heat supply - by the maximum daily air temperatures in the same period. Inclusion in analysis of additional water and heat factors of yield makes it possible not only to increase the factorality of field experiment, but also to substantially increase the conclusions validity according to the results based on the proposed mathematical model.

Keywords: mathematical simulation, field agronomic experiment, factors of the plant habitat, food mode, soil moistening, thermal mode, yield, yield factors, agricultural crops

For citation: Lichazevich A.P. Mathematical simulation for improvement of reliability of evaluation of the field agronomic experiment results. Vestsi Natsyyanal'nay akademii navuk Belarusi. Seryya agrarnykh navuk = Proceedings of the National Academy of Sciences of Belarus. Agrarian series, 2018, vol. 56, no 3, pp. 321-334 (in Russian). https://doi. org/10.29235/1817-7204-2018-56-3-321-334
}

(C) Лихацевич А.П., 2018 
Введение. В последнее время подход к математическому моделированию в растениеводстве подвергается серьезному пересмотру с позиций максимального упрощения [1]. К этому процессу все активнее подключаются специалисты, далекие от сложных форм традиционных динамических моделей продукционного процесса, пытаясь обойти структурную и алгоритмическую сложность последних [2]. Несомненно, в классических трудах наряду с практическими приложениями (прогноз продуктивности, анализ и оптимизация агротехнологий, разработка систем поддержки принятия решений и др.) декларируется еще одна важная цель создания динамических моделей - возможность их использования в качестве инструмента научного поиска и анализа закономерностей в многосложном процессе формирования урожая при развитии растительного организма в динамичных, стохастичных и во многом не поддающимся регулированию условиях внешней среды [3]. Развернутые теоретические модели, основанные на детальном описании и обобщении всего комплекса процессов в почве, растении и приземном воздухе, по-прежнему разрабатываются, но сфера их применения сужается до узких предметных исследований [1]. На передний план выходят простые эмпирические схемы разных типов и разной обоснованности, более понятные для специалистов-агрономов, которым, в принципе, они и предназначаются для практического использования [2, 4-8 и др.].

Однако, с другой стороны, предельно упрощенное «моделирование» также не может найти широкого практического применения, что вполне закономерно. Причиной являются объективные ограничения по использования предлагаемых линейных и нелинейных эмпирических формул, описывающих конечный результат действия факторов среды на урожай. Неоднократно было показано, что такие формулы при любом коэффициенте детерминации не являются действительными моделями урожайности, поскольку не имеют физического смысла, а представляют собой лишь формальное сглаживание данных конкретного эксперимента [9-11]. Эти формулы, торжественно называемые «математическими моделями», действительно справедливы для узких ограниченных условий конкретного опыта, по данным которого получены, а вот что с ними делать в других изменяющихся, неповторяющихся условиях среды не совсем понятно.

В подтверждение такому «нелицеприятному» выводу укажем, что мы не встречали в научных сборниках и журналах опубликованные результаты проверки работоспособности эмпирических формул разного вида (называемых их авторами математическими моделями урожайности), разработанных на основе теории планирования эксперимента [12] или предлагаемых без опоры на какие-либо теории, с использованием не личных опытных данных, а результатов опытов других авторов. Поэтому вполне понятны явное игнорирование большинством исследователей в этой области рекомендаций других авторов и опора только на собственные силы. Каждый пытается (вынужден) сам решать эту проблему доступными для него методами. В результате для разработки важнейших элементов технологии производства растениеводческой продукции, например системы питания, привлекаются, по-прежнему, результаты однофакторных полевых опытов, чаще без проведения какого-либо моделирования. Конечно же, точность таких рекомендаций не высока по причине отсутствия учета существенного влияния на урожай, помимо удобрений, влаго- и теплообеспеченности вегетационных периодов. Кроме того, многолетний опыт показывает, что по данным однофакторного эксперимента, учитывающего только пищевой режим, программирование (моделирование) урожая особенно в зоне «рискованного земледелия», к которой относится Беларусь, не только нецелесообразно по причине недопустимо больших ошибок в расчетах, но в отдельные годы может дать отрицательный экономический эффект.

На наш взгляд, решить данную проблему можно, повысив факторность агрономического опыта с использованием предложенной нами математической модели урожая сельскохозяйственных культур. Разработано несколько вариантов такой модели [13, 14]. В качестве данных для проверки их справедливости и оценки точности моделирования использовались результаты полевых исследований, полученные разными авторами, в разных почвенно-климатических зонах [13, 14].

В условиях Беларуси оценка разработанной модели выполнена по данным доктора с.-х. наук, профессора Н.Н. Семененко, изучавшего влияние азотного питания на урожай сельскохозяйственных культур, возделываемых на осушенных органогенных почвах Полесья [5]. Это позволило помимо доз вносимых удобрений в число учитываемых включить дополнительный фактор - контролируемые в опыте почвенные влагозапасы. 
Нельзя не отметить методическую скрупулёзность и щепетильность профессора Н.Н. Семененко в постановке уникальных полевых исследований, результаты которых по праву входят в золотой фонд аграрной науки Беларуси.

Схема взятых нами для анализа результатов пятилетних исследований Н.Н. Семененко состояла из вариантов с разными дозами азотных удобрений на одном фосфорно-калийном фоне $\left(\mathrm{P}_{80} \mathrm{~K}_{120}\right)$. Опыты проводились в годы, различающиеся по влаго- и теплообеспеченности, что, безусловно, повлияло на результаты исследований. В табл. 1 приведены данные по четырем вариантам опыта.

Т а б л и ц а 1. Влияние азотных удобрений (N), вносимых на фосфорно-калийном фоне $\mathbf{P}_{80} K_{120}$, на урожайность ячменя [5, табл. 1.12, с. 147]

T a b 1 e 1. Effect of nitrogen fertilizers (N) applied at phosphate-potassium background of $\mathbf{P}_{80} \mathbf{K}_{120}$ on barley yield [3, Table. 1.12, p. 147]

\begin{tabular}{|l|c|c|c|c|c|c|c|}
\hline \multirow{2}{*}{ Вариант опыта } & \multirow{2}{*}{ N, кг д.в/га } & \multicolumn{6}{|c|}{ Урожай, ц/га } \\
\cline { 3 - 8 } & & 2005 г. & 2006 г. & 2007 г. & 2008 г. & 2009 г. & среднее \\
\hline $\mathrm{P}_{80} \mathrm{~K}_{120}$ & 0,0 & 46,2 & 52,0 & 27,6 & 57,0 & 34,7 & 43,5 \\
\hline $\mathrm{P}_{80} \mathrm{~K}_{120}+\mathrm{N}_{60}$ & 60,0 & 63,4 & $\mathbf{6 2 , 7}$ & 37,4 & 64,8 & 42,0 & 54,1 \\
\hline $\mathrm{P}_{80} \mathrm{~K}_{120}+\mathrm{N}_{90}$ & 90,0 & $\mathbf{6 5 , 0}$ & 60,2 & 38,6 & $\mathbf{7 1 , 1}$ & $\mathbf{4 3 , 4}$ & $\mathbf{5 5 , 7}$ \\
\hline $\mathrm{P}_{80} \mathrm{~K}_{120}+\mathrm{N}_{120}$ & 120,0 & 64,6 & 53,7 & $\mathbf{3 8 , 9}$ & 70,8 & 42,1 & 54,0 \\
\hline $\mathrm{HCP}_{05}$ & 2,6 & 2,9 & 2,0 & 2,8 & 2,2 & - \\
\hline
\end{tabular}

Согласно данным табл. 1, как указано автором опыта, наиболее эффективной является доза азота $\mathrm{N}_{90}$. Однако заметим, что 2006 и 2007 гг. выпадают из общей картины. Причем ясно, что полученный в опытах разброс в дозах, дающих максимальный урожай, является следствием различий во влаго- и теплообеспеченности вегетационных периодов в годы исследований.

С помощью математического моделирования повысим факторность рассматриваемого опыта. Покажем, что учет большего числа урожаеформирующих факторов позволяет уточнить выводы, в том числе и о дозе азота, дающей максимальный урожай ячменя на осушенных органогенных почвах Полесья (в данном случае на фосфорно-калийном фоне $\mathrm{P}_{80} \mathrm{~K}_{120}$ ).

Для анализа используем простейшую математическую модель урожая, которая по форме несколько отличается от вариантов модели, представленных нами ранее [13, 14], но позволяет получить более точный результат. При этом считаем своей обязанностью выразить признательность и благодарность доктору физико-математических наук, профессору В.В. Веденяпину (МФТИ, Москва, Россия) за ценные замечания и предложения, учет которых позволил наиболее корректно представить аналитическую часть обоснования модели урожая.

Обоснование математической модели урожая. Моделирование влияния факторов среды на урожай выполним на основе физического принципа баланса причинно-следственных взаимодействий в замкнутой физической системе, который относительно урожая и воздействующих на него факторов среды формулируется следующим образом:

1) бесконечно малое изменение урожая $Y$ под воздействием какого-то фактора $R_{i}$ (влага, пища, тепло) пропорционально произведению восприимчивости урожая к действию данного фактора на характеристику воздействия этого фактора на урожай;

2) каждый из факторов, действующих на урожай, сообщает ему такое же изменение, как если бы других факторов не было.

Формально принцип баланса причинно-следственных взаимодействий можно представить в виде следующего уравнения:

$$
\frac{\partial Y}{\partial R_{i}}=\alpha_{i} f_{i}\left(Y, R_{i}\right) g_{i}\left(R_{i}\right)
$$

где $\partial Y / \partial R_{i}$ - частная производная функции $Y$ по $i$-му аргументу, соответствующая скорости изменения урожая $Y$ при изменении $i$-го фактора $R_{i}$, при условии, что другие факторы (аргумен- 
ты функции) не меняются; $\alpha_{i}-$ безразмерная константа пропорциональности воздействия $i$-го фактора $R_{i}$ на урожай $Y ; f_{i}\left(Y, R_{i}\right)$ - функция, характеризующая восприимчивость урожая $Y$ по отношению к воздействию $i$-го фактора; $g_{i}\left(R_{i}\right)$ - характеристика воздействия $i$-го фактора $R_{i}$ на урожай $Y$ (безразмерная величина).

Поскольку растения как объект воздействия окружающей среды накладывают двустороннее ограничение (по минимуму и максимуму) на каждый фактор, упростим задачу и будем рассматривать только интересующие нас области функции (1). Например, при направленном регулировании пищевого режима наиболее предпочтительно построение модели в области с повышением доз вносимых удобрений от минимума до оптимального уровня, а при регулировании водного режима растений следует отдельно анализировать области либо снижения почвенной влажности от максимума до оптимума (при осушении почвы) или ее целенаправленного повышения от минимума до оптимума (при орошении). В свою очередь, поскольку тепловой фактор в полевых опытах, как правило, не регулируется, в анализе можно использовать как область роста теплового воздействия на урожай (от оптимума до максимума), так и область недостатка тепла (от оптимума до минимума). Выбор зависит от тепловых предпочтений исследуемой культуры и региона ее возделывания (жаркий юг, умеренный по теплу центр или прохладный север).

Заметим, что разработкой математических моделей урожая занимались и до нас многие исследователи, заслугой которых является установление закономерностей влияния факторов среды на урожай. Например, в зависимостях, приведенных в статье [15], пособии ${ }^{1}$ и других работах, как основной аргумент присутствует отклонение фактических значений факторов среды (доз вносимых удобрений, почвенных влагозапасов, температур воздуха и др.) от их оптимума, что подтверждает важность величины данного отклонения, определяющего потенциал формирования урожая. Кроме данного факта при построении функции (1) нами учтены установленные опытным путем следующие закономерности $[3,9-11,15,16]$ :

1) растения являются системой с памятью, т.е. прирост урожая зависит от условий его формирования, определяемых факторами среды;

2) с приближением условий среды к оптимуму прирост урожая замедляется;

3) если условия среды (влага, пища, тепло и др.) находятся в оптимуме, то растения образуют максимум урожая;

4) при отклонении фактора от оптимального значения в любую сторону (к минимуму или к максимуму) урожай снижается;

5) урожаеформирующие факторы равноценны по влиянию на растения и не могут заменить друг друга;

6) наибольшее влияние на снижение урожая оказывает фактор, находящийся в минимуме.

Согласно установленным закономерностям, соблюдая баланс размерностей, можем представить составные элементы выражения (1), формализующего принцип баланса причинно-следственных взаимодействий в системе «факторы среды (причина) - урожай (следствие)», в следующей форме:

- восприимчивость (проводимость) урожая к действию $i$-го фактора определяется произведением относительной величины урожая (по $i$-му фактору) на максимальную величину характеристики управляющего воздействия данного фактора:

$$
f_{i}\left(Y, R_{i}\right)=\frac{Y}{R_{i}-R_{i(\min , \max )}} \frac{R_{i(\mathrm{opt})}-R_{i(\min , \max )}}{R_{i}-R_{i(\min , \max )}}=Y \frac{R_{i(\mathrm{opt})}-R_{i(\min , \max )}}{\left(R_{i}-R_{i(\min , \max )}\right)^{2}}
$$

где $Y$ - урожай; $R_{i}$ - фактическое значение $i$-го фактора среды; $R_{i(\mathrm{pt})}$ - оптимальное значение $i$-го фактора, при котором урожай достигает своего максимума; $R_{i(\min , \max )}-$ минимальное (или максимальное) значение $i$-го фактора, при котором урожай перестает формироваться и погибает;

${ }^{1}$ Дмитренко В.П. Оценка влияния температуры воздуха и осадков на формирование урожая основных зерновых культур : метод. пособие. - Л. : Гидрометеоиздат, 1976. - 49 с. 
- характеристика управляющего воздействия $i$-го фактора $R_{i}$ на урожай $Y$ подобна градиенту, который трактуется, например в мелиорации, как «понижение напора, отнесенное к пути фильтрации»². Обозначим

$$
g_{i}\left(R_{i}\right)=\frac{R_{i(\mathrm{opt})}-R_{i}}{R_{i}-R_{i(\min , \max )}} .
$$

Здесь под «напором» понимается разность $\left(R_{i(\mathrm{opt})}-R_{i}\right)$, а «путь фильтрации» соответствует разности $\left(R_{i}-R_{i(\min , \max )}\right)$.

С учетом зависимостей (2), (3) дифференциальное уравнение (1) можно привести к такому виду:

$$
\frac{\partial Y}{\partial R_{i}}=Y \psi_{i}\left(R_{i}\right)
$$

где

$$
\psi_{i}\left(R_{i}\right)=\frac{f_{i}\left(Y, R_{i}\right) g_{i}\left(R_{i}\right)}{Y} .
$$

Тогда система уравнений (1)-(5), объединяющая воздействие $n$-факторов среды на урожай, имеет общее решение:

$$
Y\left(R_{1}, R_{2}, \ldots, R_{n}\right)=\exp \left(\sum_{i=1}^{n} \varphi_{i}\left(R_{i}\right)\right)
$$

где функции $\psi_{i}\left(R_{i}\right)$ и $\varphi_{i}\left(R_{i}\right)$ связаны соотношениями $\frac{d \varphi_{i}}{d R_{i}}=\psi_{i}$.

Соответственно, из выражений (1)-(3) с учетом уравнений (4)-(6) получаем

$$
\frac{Y}{Y_{\max }}=\exp \left\{-\sum_{i=1}^{n}\left[a_{i}\left(\frac{R_{\text {iopt }}-R_{i}}{R_{i}-R_{i(\min , \max )}}\right)^{2}\right]\right\},
$$

где $Y$ - фактический урожай; $Y_{\max }$ - максимум урожая; $a_{i}$ - коэффициент пропорциональности воздействия $i$-го фактора среды на урожай; $n$ - количество учитываемых факторов; $R_{i o p t}$ - оптимальное значение $i$-го фактора среды, при котором достигается максимум урожая; $R_{i}$ - фактическое значение $i$-го фактора среды; $R_{i(\min , \max )}$ - значения $i$-го фактора среды, при которых урожай перестает формироваться и погибает.

Заметим, что благодаря мультипликативной форме зависимости (7) в ней, во-первых, априори соблюдается упомянутый выше «закон минимума». Во-вторых, в отличие от использования известной методики планирования эксперимента [12], целью которой является построение регрессионных зависимостей, представляющих причинно-следственные взаимодействия в замкнутой физической системе в виде многочленных полиномов с ограниченным числом переменных, мультипликативная функция (7) не только является действительной физической моделью урожая, но и может включать неограниченное число переменных.

Наиболее сложным и ответственным действием в предлагаемой нами схеме математического моделирования является установление исходных зависимостей вида (2), (3). Как правило, эти зависимости весьма сложно строить на основе известных физических законов природы. Чаще исследователи вынуждены ограничиваться эмпирическим подходом, результативность которого зависит от квалификации, опыта и интуиции автора анализа. Но в любом случае при построении физической модели объекта исследований с использованием любого вида формул (теоретических или эмпирических) необходимо соблюдать следующие условия: необходимым условием является полное соответствие предлагаемых зависимостей физическим закономерностям, установленным в опытах; достаточное условие состоит в обязательном соблюдении баланса размерностей всех показателей, входящих в предлагаемые формулы. Использование отличающихся

\footnotetext{
${ }^{2}$ Мелиорация : энцикл. справ. / редкол.: И.П. Шамякин (гл. ред.) [и др.] ; под общ. ред. А. И. Мурашко. - Минск : Белорус. Совет. Энцикл., 1984. - 567 с.
} 
от зависимостей (2) и (3) выражений для раскрытия функций восприимчивости (проводимости) объекта к действию фактора и характеристики управляющего воздействия данного фактора на объект при обязательном выполнении необходимого и достаточного условий, как было сделано в работах [13] и [14], конечные расчетные зависимости будут различаться по форме, однако в своей области определения, границы которой фиксируются по данным конкретного опыта, все получаемые формулы дадут близкий результат, что наглядно показано в [13], [14].

В полевом опыте Н.Н. Семененко (см. табл. 1) в качестве регулируемого фактора питания растений используется не суммарный азотно-фосфорно-калийный фон, а только его часть азотные удобрения, которые и будем учитывать при моделировании урожая. Раскроем формулу (7), добавив к регулируемому азотному питанию нерегулируемые в опыте факторы - влагои теплообеспеченность вегетации. В этом случае

$$
\frac{Y}{Y_{\max }}=\exp \left\{-\left[a_{\mathrm{N}}\left(\frac{\mathrm{N}_{\mathrm{opt}}-\mathrm{N}}{\mathrm{N}-\mathrm{N}_{\text {min }}}\right)^{2}+a_{W}\left(\frac{W_{\mathrm{opt}}-W}{W-W_{\min (\max )}}\right)^{2}+a_{T}\left(\frac{T_{\mathrm{opt}}-T}{T-T_{\min (\max )}}\right)^{2}\right]\right\},
$$

где $a_{\mathrm{N}}, a_{W}, a_{T}$ - коэффициенты пропорциональности влияния азотного питания, влаги и тепла соответственно на урожай; $\mathrm{N}_{\text {opt }}, W_{\text {opt }}, T_{\text {opt }}$ - оптимальные количества азота, почвенной влаги и тепла соответственно, при которых достигается максимум урожая; $\mathrm{N}_{\min }, W_{\min (\max )}, T_{\min (\max )}-$ количества азота, почвенной влаги и тепла соответственно, при которых урожай перестает формироваться и погибает.

Полученные нами обобщающая функция (7), ее частное выражение (8), а также другие подобные формулы, приведенные в работах $[13,14]$, представляют собой действительную математическую модель урожая. Эти зависимости, обобщающие воздействие факторов среды на урожай, можно с успехом применять в любых регионах, например, на территории Российской Федерации, Беларуси, а также в других почвенно-климатических условиях, используя их, например, для программирования (моделирования) урожая, оптимизации распределения ресурсов в земледелии и прочих целей.

Проверка справедливости математической модели урожая. Проанализируем работоспособность представленной выше математической модели урожая (7) с привлечением результатов полевого опыта профессора Н.Н. Семененко (см. табл. 1). В расчетную формулу вида (8) будем поочередно включать сначала один фактор (потребляемая растениями пища), затем два (пища и водный режим) и, наконец, три фактора (пища, водный и тепловой режимы), прослеживая изменение точности моделирования. В качестве показателя теплового режима будем использовать максимальные суточные температуры воздуха, измерение которых без особых навыков может освоить любой исследователь, в отличие от среднесуточной температуры воздуха, получение которой под силу только специально обученным специалистам на метеостанциях или соответствующим образом оборудованных метеопостах.

1. В табл. 2 (столбец 7) показаны результаты расчета урожая по сокращенной формуле (8), учитывающей только дозу азота $(\mathrm{N})$ при игнорировании факторов влаги и тепла (т.е. при $a_{W}=a_{T}=0$ ). Стандартное (среднеквадратическое) отклонение вычисленных урожаев от измеренных в нашем случае составило 12,24 ц/га (столбец 8) при следующих значениях опорных показателей математической модели урожая: $Y_{\max }=55,0$ ц/га; $a_{\mathrm{N}}=1 ; \mathrm{N}_{\text {орt }}=90$ кг д.в/га; $\mathrm{N}_{\min }=-188$ кг д.в/га. Полученное отрицательное значение минимального количества азота $\left(\mathrm{N}_{\min }=-188\right.$ кг д.в/га), при котором урожай перестает формироваться и погибает, указывает на то, что в почве до внесения удобрений изначально содержалось азота не менее 188 кг д.в/га $\left(\mathrm{N}_{\text {почвы }}>\mathrm{N}_{\min }\right)$. Заметим, что органогенная почва, на которой проводились исследования, достаточно плодородна. На варианте без удобрений урожайность ячменя колебалась в зависимости от условий года от 22,5 до 45,8 ц/га [5, с. 147].

Как видим, в данном случае полученная ошибка расчета $(\delta=12,24$ ц/га) достигает четверти от среднемноголетнего урожая ячменя, что подтверждает нецелесообразность построения каких-либо математических моделей в земледелии с опорой на однофакторный эксперимент по причине их неточности. Этот вывод наглядно объясняет причину провала попыток программирования урожаев в условиях Беларуси с опорой только на регулирование пищевого режима 
Т а б л и ц а 2. Сравнение измеренной в поле и вычисленной урожайности ячменя с привлечением разных урожаеформирующих факторов

$\mathrm{T} \mathrm{a} \mathrm{b} 1 \mathrm{e} \quad 2$. Comparison of measured in field and calculated barley yield using various yield forming factors

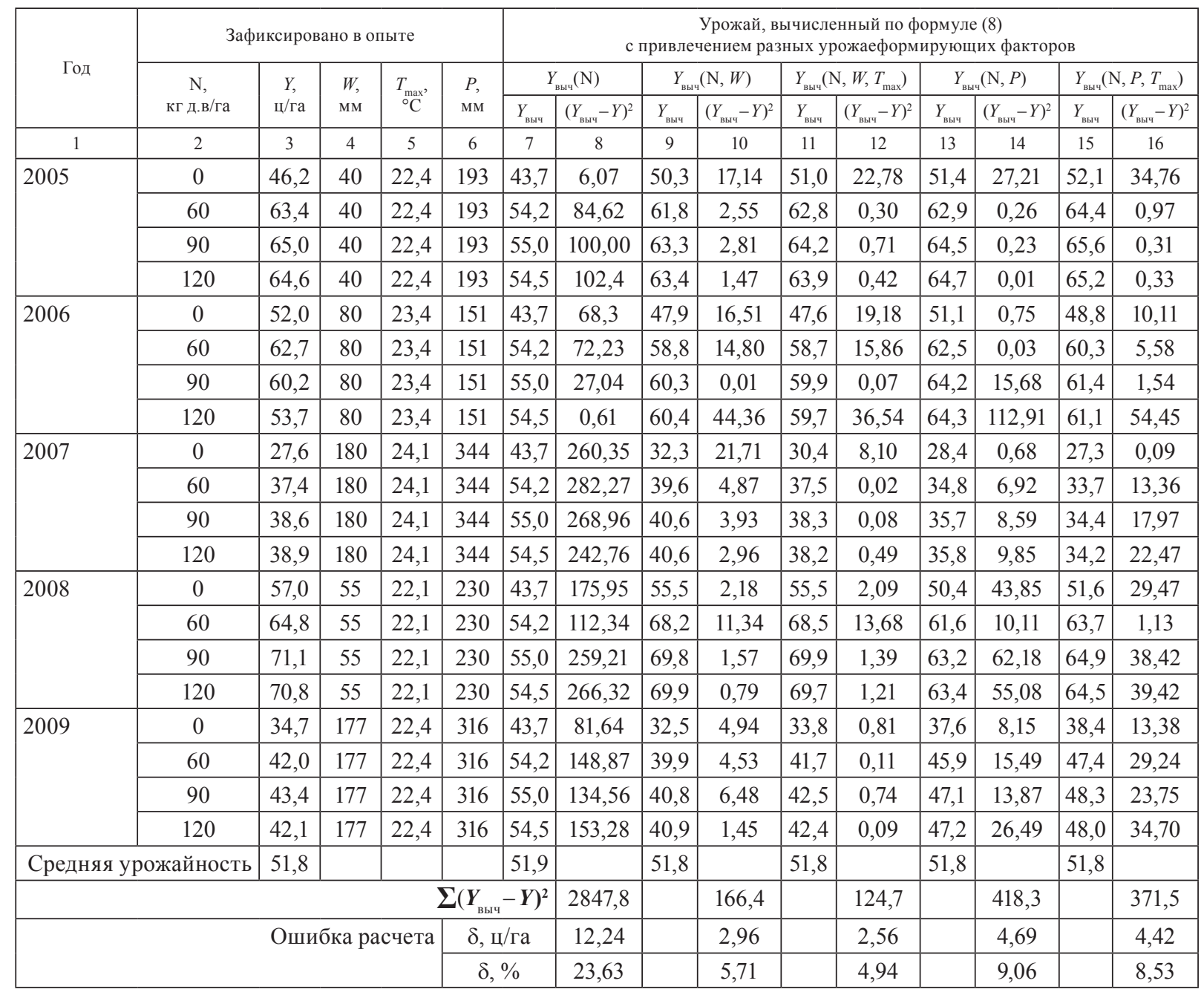

растений. В зоне рискованного земледелия, характеризующейся значительными колебаниями влаго- и теплообеспеченности вегетационных периодов, невозможно давать уверенные прогнозы урожайности из-за непредсказуемости погодных условий. Необходимо учитывать, что точность заблаговременного прогнозирования урожая (до начала вегетации) всегда будет соответствовать точности долгосрочных прогнозов погоды.

2. Сделаем следующий шаг, опираясь на ретроспективу опыта, добавим в модель урожая водный фактор - почвенные влагозапасы, динамика которых контролировалась в опыте Н.Н. Семененко. В монографии приведены значения влажности корнеобитаемого слоя почвы, осредненные по фазам развития культуры [5, рис. 1.5, с. 137$]$.

Для установления значимости данного фактора и его влияния на конечный урожай оценим связь урожая ячменя с влагозапасами почвы в разные фазы развития. Анализ результатов опыта показывает, что в первые три фазы развития ячмень положительно отзывается на повышенные влагозапасы, а в фазы 4-6 при высоких почвенных влагозапасах урожай, наоборот, начинает снижаться [5]. Кроме того, из приведенных в монографии Н.Н. Семененко данных следует, что наиболее тесной является связь урожая ячменя с продуктивными влагозапасами в 6-ю фазу (созревание культуры), причем культура отвечает на переувлажнение в эту фазу достоверным снижением урожая (рис. 1).

Показательно, что на органогенных почвах в южном регионе Беларуси сброс излишков почвенной влаги в фазу созревания является важным фактором повышения урожайности ячменя. Данный вывод весьма важен для повышения продуктивности осушаемых почв Полесья. 


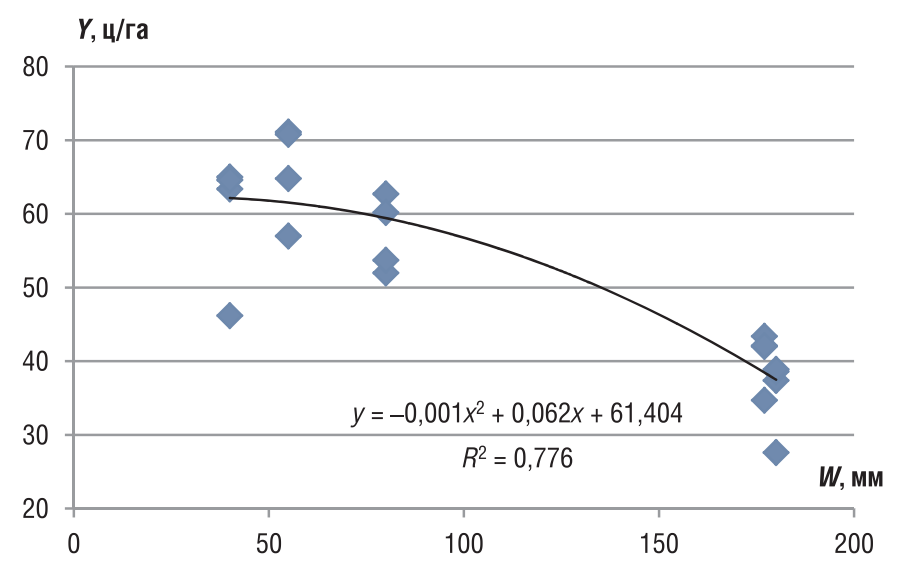

Рис. 1. Зависимость урожая ячменя от наличия в почве продуктивной влаги в фазу созревания

Fig. 1. Correlation of barley yield on productive moisture level in soil during ripening phase

Моделирование связи урожая ячменя по схеме (8), но не с одним, а с двумя урожаеформирующими факторами (дозами вносимого азота и продуктивными влагозапасами в фазу созревания) приводит к существенно лучшему результату, чем однофакторный эксперимент. Среднеквадратическое отклонение вычисленных урожаев от измеренных, согласно данным расчета (см. табл. 2, столбец 10), уменьшилось в 4 раза и более - с 12,24 до 2,96 ц/га и составило всего $5,7 \%$ от среднего за годы исследований урожая при следующих значениях опорных показателей математической модели: $Y_{\max }=70,5$ ц/га; $a_{\mathrm{N}}=1 ; \mathrm{N}_{\text {орt }}=106$ кг д.в/га; $\mathrm{N}_{\min }=-220$ кг д.в/га; $a_{W}=1$; $W_{\text {opt }}=51 \mathrm{мм} ; W_{\min }=6$ мм.

Как видим, введение в математическую модель урожая двух факторов позволило на основе обобщенного уравнения (8) при $a_{\mathrm{N}}=1, a_{W}=1, a_{T}=0$ предложить достаточно точную формулу для расчета (моделирования) урожая ячменя, возделываемого на органогенных почвах в южном регионе Беларуси (согласно рис. 2, коэффициент детерминации близок к $R^{2}=0,95$ ).

Вид полученной расчетной формулы, учитывающей конкретные значения опорных показателей двухфакторной модели, достаточно прост:

$$
Y=70,5 \exp \left\{-\left[\left(\frac{106-\mathrm{N}}{\mathrm{N}+220}\right)^{2}+\left(\frac{51-W}{W-6}\right)^{2}\right]\right\},
$$

где $Y$ - урожай ячменя, ц/га; $\mathrm{N}$ - доза вносимого азота, кг д.в./га; $W$ - среднее количество влаги, содержащейся в корнеобитаемом слое почвы в фазу созревания культуры, мм.

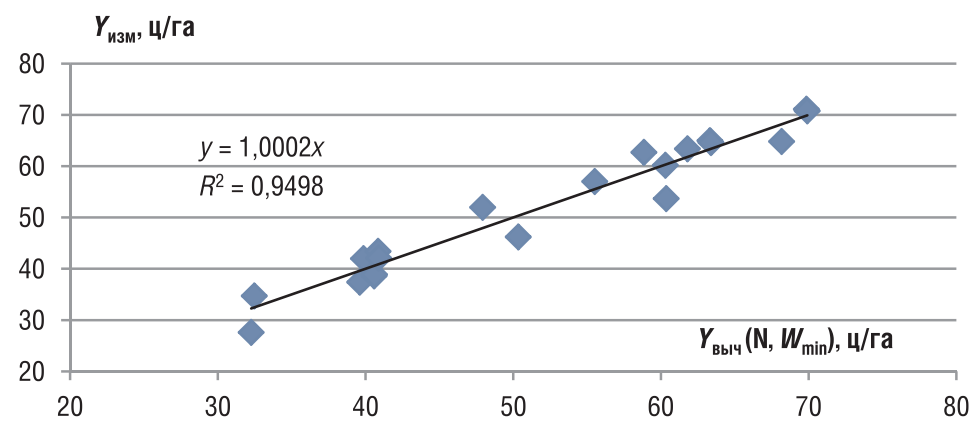

Рис. 2. Сравнение измеренных в поле и вычисленных по формуле (9) урожаев ячменя с учетом вносимого азота и средних продуктивных влагозапасов, содержащихся в почве в фазу созревания

Fig. 2. Comparison of measured in field and calculated according to formula (9) barley yield considering applied nitrogen and the average productive moisture reserves contained in soil during ripening phase 
Результаты вычислений по формуле (9) весьма тесно коррелируют с наблюдаемыми непосредственно в поле (см. рис. 2). Стандартная ошибка вычислений $(2,96$ ц/га) близка к ошибке опыта (табл. 1 - строка $\mathrm{HCP}_{05}$; табл. 2 - столбец 10), что является подтверждением справедливости предложенной модели урожая (7), в данном случае учитывающей два фактора (вносимый азот и продуктивные влагозапасы в фазу созревания ячменя).

3. Добавим в модель урожая третий фактор - температурные условия вегетации, полностью используя возможности расчетной формулы (8). Из данных метеостанции «Полесская», расположенной вблизи опытов профессора Н.Н. Семененко, нами выбраны суточные максимальные температуры воздуха в 2005-2009 гг. за май-июль и для наглядности определены максимальные температуры воздуха, средние за сутки в выбранном трехмесячном диапазоне.

Моделирование связи урожая ячменя по схеме (8) с тремя урожаеобразующими факторами (дозами вносимого азота, продуктивными влагозапасами в фазу созревания и средними за май-июль максимальными суточными температурами воздуха) еще более приблизило результаты расчета к опытным данным (рис. 3, таблица 2 - столбец 11). Среднеквадратическое отклонение вычисленных урожаев от измеренных уменьшилось до 2,56 ц/га и не превысило ошибку опыта (табл. 1 - строка $\mathrm{HCP}_{05}$; табл. 2 - столбец 12), составляя всего около 5,0 \% от среднего за годы исследований урожая при следующих значениях опорных показателей математической модели (8): $Y_{\max }=71,4$ ц/га; $a_{\mathrm{N}}=1 ; \mathrm{N}_{\text {opt }}=100$ кг д.в/га; $\mathrm{N}_{\min }=-208$ кг д.в/га; $a_{W}=1 ; W_{\text {opt }}=52$ мм; $W_{\min }=3 \mathrm{~mm} ; a_{T}=1 ; T_{\max (\text { (opt })}=22,5^{\circ} \mathrm{C} ; T_{\max (\min )}=19^{\circ} \mathrm{C}$.

$$
\boldsymbol{Y}_{\text {изм }}, \text { ц/га }
$$

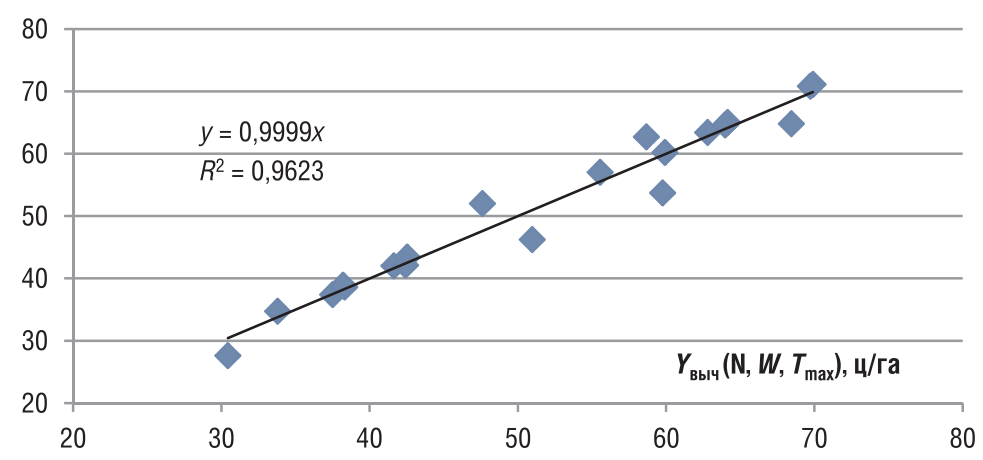

Рис. 3. Сравнение измеренных в поле и вычисленных по формуле (10) урожаев ячменя

Fig. 3. Comparison of measured in field and calculated according to formula (10) barley yield

Подставляя в формулу (8) найденные значения опорных показателей модели, получим окончательную расчетную зависимость, связывающую урожайность ячменя в почвенно-климатических условиях опыта с тремя урожаеформирующими факторами (азотным питанием, почвенными влагозапасами и максимальными температурами воздуха):

$$
Y=71,4 \exp \left\{-\left[\left(\frac{100-\mathrm{N}}{\mathrm{N}+208}\right)^{2}+\left(\frac{52-W}{W-3}\right)^{2}+\left(\frac{22,5-T_{\max }}{T_{\max }-19}\right)^{2}\right]\right\},
$$

где $T_{\max }$ - максимальная суточная температура воздуха в годы исследований, средняя за майиюль, ${ }^{\circ} \mathrm{C}$.

Схема полевых исследований профессора Н.Н. Семененко никоим образом не подстраивалась под какое-либо моделирование, поэтому результаты сравнения опытных данных с полученными расчетом по формулам (8)-(10) устраняют всякие сомнения в справедливости математической модели урожая (7). Однако следует подчеркнуть, что предложенные на основе эмпирических схем любые математические модели урожая имеют ограничения в области применения. Их использование, как и у эмпирических формул, допустимо только в пределах, близких к крайним значениям показателей, зафиксированных в опытах и участвующих в определении 
опорных показателей математической модели урожая. Данный диапазон для ячменя, возделываемого на осушенных органогенных почвах в южном регионе Беларуси на фосфорно-калийном фоне $\mathrm{P}_{80} \mathrm{~K}_{120}$, соответствует границам изменения факторов урожая, зафиксированным в опытах Н.Н. Семененко (см. табл. 1):

$$
0 \leqslant \mathrm{~N} \leqslant 220 \text { кг д.в/га; } 40 \leqslant W \leqslant 180 \text { мм; } 22,0 \leqslant T_{\max \text { (ср. за май-июль) }} \leqslant 24,5^{\circ} \mathrm{C} \text {. }
$$

Повышение числа учитываемых в агрономическом опыте факторов путем использования метеорологической информации. Для демонстрации возможностей математического моделирования помимо основного показателя водного режима - почвенных влагозапасов в корнеобитаемом слое, которые контролируются далеко не во всех агрономических опытах, используем более доступный для агрономов показатель - атмосферные осадки (обозначим их символом $P$ ), замерять которые существенно проще, чем влажность почвы в течение вегетации.

Из данных упомянутой выше метеостанции «Полесская» нами выбраны атмосферные осадки и просуммированы в годы исследований (2005-2009 гг.) за май-июль. На рис. 4 приведено сравнение измеренных в поле и вычисленных по формуле (9) урожаев ячменя (табл. 2, столбец 13) с учетом вносимых азотных удобрений и суммарных за май-июль атмосферных осадков (т.е. при $\left.a_{\mathrm{N}}=1, a_{P}=1, a_{T}=0\right)$.

Различие (среднеквадратическое отклонение) между урожаями, полученными в поле и вычисленными по азотным удобрениям и атмосферным осадкам, составило 4,69 ц/га, или около 9,1\% от среднего за годы исследований урожая (табл. 2 - столбец 14) при следующих значениях опорных показателей математической модели: $Y_{\max }=64,8 ц / г a ; a_{\mathrm{N}}=1 ; \mathrm{N}_{\mathrm{opt}}=109$ кг д.в/га; $\mathrm{N}_{\min }=-227$ кг д.в/га; $a_{P}=1 ; P_{\text {opt }}=183$ мм; $P_{\max }=553$ мм.

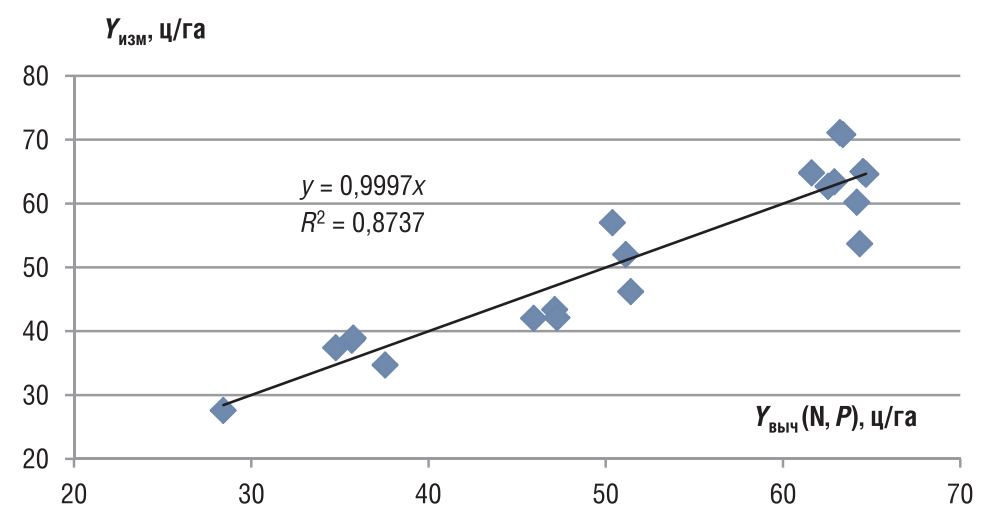

Рис. 4. Сравнение измеренных в поле и вычисленных урожаев ячменя с учетом вносимых азотных удобрений и суммарных за май-июль атмосферных осадков

Fig. 4. Comparison of measured in field and calculated barley yield considering applied nitrogen fertilizers and total precipitation for May-July period

На рис. 5 приведено сравнение измеренной в поле и вычисленной урожайности ячменя с учетом трех факторов: вносимых азотных удобрений, суммарных за май-июль атмосферных осадков и максимальной суточной температуры воздуха в годы исследований, средней за май-июль (табл. 2 , столбцы 15,16 ). Среднеквадратическое отклонение вычисленных урожаев от измеренных составило 4,42 ц/га, т.е. около $8,5 \%$ от среднего за годы исследований урожая при следующих значениях опорных показателей модели: $Y_{\max }=72,3$ ц/га; $a_{\mathrm{N}}=1 ; \mathrm{N}_{\mathrm{opt}}=95$ кг д.в/га; $\mathrm{N}_{\min }=-198$ кг д.в/га; $a_{P}=1 ; P_{\text {opt }}=155$ мм; $P_{\max }=603$ мм; $a_{T}=1 ; T_{\max (\text { opt })}=20,7^{\circ} \mathrm{C} ; T_{\max (\min )}=16,7^{\circ} \mathrm{C}$.

Точность моделирования с использованием метеоданных, несомненно, можно повысить, если в качестве показателя водного режима использовать суммарные атмосферные осадки не общие за май-июль месяцы, а устанавливать связь урожая ячменя с суммой осадков за конкретные фазы вегетации культуры. Но поскольку этих данных у нас нет, ограничимся общей суммой осадков. Вместе с тем, как следует из полученной оценки сравнения (см. рис. 5), пользуясь даже 


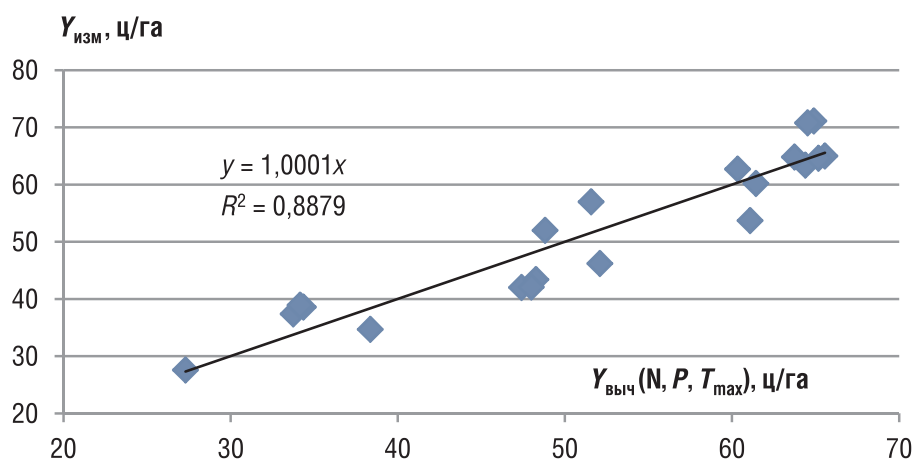

Рис. 5. Сравнение измеренных в поле и вычисленных урожаев ячменя с учетом вносимых азотных удобрений, суммарных за май-июль атмосферных осадков и максимальных суточных температур воздуха в годы исследований, средних за май-июль

Fig. 5. Comparison of measured in field and calculated barley yield considering applied nitrogen fertilizers, total precipitation for May-July period and maximum daily air temperature during research years, average for May-July period

Т а б л и ц а 3. Опорные значения вариантов математической модели урожая ячменя на органогенных почвах в южном регионе Беларуси при разном количеством учитываемых факторов

$\mathrm{T}$ a b 1 e 3. Reference values of variants of mathematical model for barley yield on organogenic soils in the southern region of Belarus at different number of factors considered

\begin{tabular}{|l|c|c|c|c|c|}
\hline \multirow{2}{*}{ Опорные показатели модели } & \multicolumn{5}{|c|}{ Учитываемые факторы } \\
\cline { 2 - 6 } & $\mathrm{N}$ & $\mathrm{N}, W$ & $\mathrm{~N}, W, T_{\max }$ & $\mathrm{N}, P$ & $\mathrm{~N}, P, T_{\max }$ \\
\hline$Y_{\max }$, ц/га & 55,0 & 70,5 & 71,4 & 64,8 & 72,3 \\
\hline$a_{\mathrm{N}}$ & 1,0 & 1,0 & 1,0 & 1,0 & 1,0 \\
\hline$a_{W}, a_{P}$ & 0 & 1,0 & 1,0 & 1,0 & 1,0 \\
\hline$a_{T}$ & 0 & 0 & 1,0 & 0 & 1,0 \\
\hline $\mathrm{N}_{\text {opt }}$, Кг д.в/га & 90 & $\mathbf{1 0 6}$ & $\mathbf{1 0 0}$ & $\mathbf{1 0 9}$ & $\mathbf{9 5}$ \\
\hline $\mathrm{N}_{\min }$, Кг Д.В/га & -188 & -220 & -208 & -227 & -198 \\
\hline$W_{\text {opt }}, P_{\text {opt }}$, мм & - & 51 & 52 & 183 & 155 \\
\hline$W_{\min }, P_{\max }$, Мм & - & 6 & 3 & 553 & 603 \\
\hline$T_{\max (\text { opt }},{ }^{\circ} \mathrm{C}$ & - & - & 22,5 & - & 20,7 \\
\hline$T_{\max (\min )},{ }^{\circ} \mathrm{C}$ & - & - & 19,0 & - & 16,7 \\
\hline
\end{tabular}

такой приближенной моделью, можно получать вполне приемлемые результаты моделирования (программирования) урожая.

В табл. 3 представлены опорные значения всех рассмотренных выше вариантов математической модели урожая ячменя на органогенных почвах в южном регионе Беларуси, протестированных по данным полевого опыта профессора Н. Н. Семененко.

Как показывают данные таблицы, максимальный урожай ячменя на фосфорно-калийном фоне $\mathrm{P}_{80} \mathrm{~K}_{120}$ может быть получен не при дозе азота $\mathrm{N}_{90}$, что следует из однофакторного эксперимента, а при дозах азота в пределах $\mathrm{N}_{95}-\mathrm{N}_{109}$. Уточнить дозу внесения азота, дающую максимум урожая, можно с помощью графика, построенного по данным табл. 3 (рис. 6).

Согласно рис. 6 , максимальный урожай ячменя (74,5 ц/га) может быть получен при дозах удобрений $\mathrm{N}_{(100-102)} \mathrm{P}_{80} \mathrm{~K}_{120}$. Заметим, что выводы по результатам однофакторного опыта (см. табл. 1) и многофакторного (см. табл. 3) существенно различаются между собой. Неточности в выводах исключаются при использовании в анализе опытных данных представленной выше математической модели урожая, позволяющей без особых затрат повысить факторность полевого агрономического эксперимента, используя для этого метеорологическую информацию. 


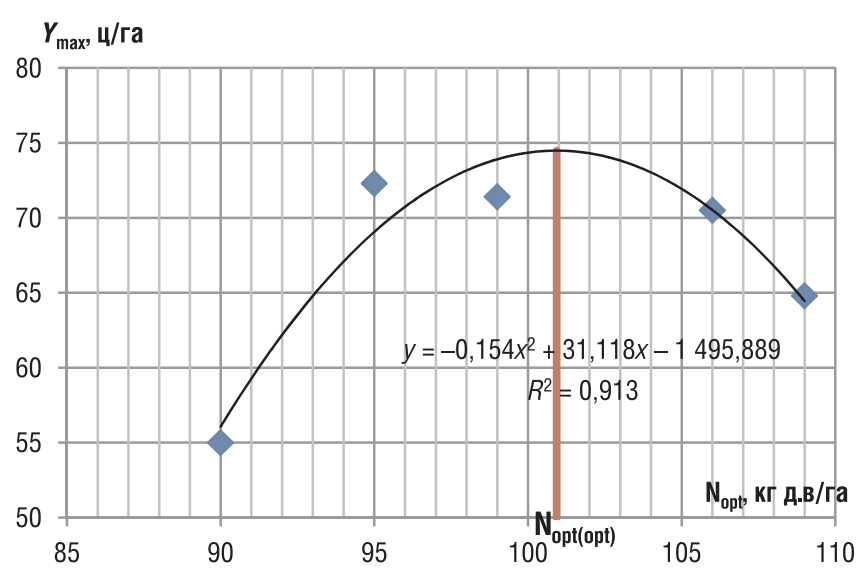

Рис. 6. Зависимость максимального урожая ячменя от дозы азота в рассмотренных вариантах моделирования

Fig. 6. Correlation of the maximum barley yield with nitrogen dose in the considered modeling options

Заключение. Из приведенных результатов анализа следует, что по данным однофакторного эксперимента, учитывающего только пищевой режим, программирование (моделирование) урожая в условиях Беларуси нецелесообразно по причине недопустимо больших ошибок в расчетах.

Для повышения точности выводов к данным однофакторного агрономического опыта, связывающего урожай культуры только с дозами вносимых удобрений, рекомендуется на основе предложенной математической модели добавлять водный и тепловой факторы урожая, в качестве которых можно использовать атмосферные осадки и максимальные суточные температуры воздуха соответственно, это позволит повысить факторность полевого опыта и обоснованность выводов по его результатам.

Схема агрономического опыта, имеющего целью установление зависимости урожая культуры от урожаеобразующих факторов, должна обязательно включать варианты с заведомо высокими дозами удобрений, не ведущими к повышению урожая в исследуемых условиях. Только в этом случае при обработке результатов опыта можно эффективно применять математическое моделирование урожая.

Предложенная математическая модель урожая (7), (8), основанная на формулах типа (2), (3), дает достаточно точные результаты в диапазоне значений урожаеформирующих факторов, зафиксированных в опытах. Она пригодна для разработки научно обоснованных рекомендаций по оптимизации питания культуры как в условиях нерегулируемого водного режима, так и на объектах сельскохозяйственной гидромелиорации. При необходимости получения полных рекомендаций достаточно на основе полученной модели построить эволюционную модель, предсказывающую урожай (данные типа табл. 1) в нескольких вариантах: вариант I (теплица) - здесь регулируются и температура, и влага, и питание; вариант II (условия гидромелиорации) - регулируются водный режим и питание, но не температурный режим; вариант III - регулируется только внесение удобрений.

\section{Список использованных источников}

1. Абнормальные формы функции отклика «удобрения-продуктивность»: полевые наблюдения и модельный анализ / А. Г. Топаж [и др.] // Изв. Тимирязев. с.-х. акад. - 2015. - Вып. 2. - С. 15-27.

2. Прошкин, В.А. Моделирование эффективности минеральных удобрений по показателям агрохимических свойств почвы / В. А. Прошкин // Агрохимия. - 2012. - № 7. - С. 16-27.

3. Полуэктов, Р. А. Динамические модели агроэкосистемы / Р. А. Полуэктов. - Л. : Гидрометеоиздат, 1991. -312 с.

4. Валге, А.М. Математическое моделирование урожайности многолетних трав / А.М. Валге, Э.А. Папушин, А. Н. Перекопский // Вестн. Рос. акад. с.-х. наук. - 2013. - № 5. - С. 8-10.

5. Семененко, Н.Н. Торфяно-болотные почвы Полесья: трансформация и пути эффективного использования / Н.Н. Семененко. - Минск : Беларус. навука, 2015. - 282 с.

6. Степуро, М. Ф. Использование методов математического моделирования при оценке систем удобрений и оптимизации минерального питания свеклы столовой / М.Ф. Степуро // Овощеводство : сб. науч. тр. / Нац. акад. наук Беларуси, Ин-т овощеводства. - Минск, 2012. - Вып. 20. - С. 245-254. 
7. Степуро, М.Ф. Использование методов математического моделирования при оптимизации систем удобрения моркови / М. Ф. Степуро // Картофель и овощи. - 2013. - № 1. - С. 19-21.

8. Шаповалов, Н. К. Математическое моделирование управления продукционным процессом на посевах сахарной свеклы / Н. К. Шаповалов, И. Е. Солдат // Достижения науки и техники АПК. - 2013. - №2. - С. $29-31$.

9. Вахонин, Н.К. Методологические принципы формирования задач оптимизации растениеводства / Н. К. Вахонин // Мелиорация переувлажн. земель. - 2007. - №2 (58). - С. 73-79.

10. Вахонин, Н.К. Концептуальные основы моделирования урожайности в системе принятия решений по регулированию водного режима / Н. К. Вахонин // Мелиорация. - 2014. - №2 (72). - С. 7-15.

11. Вахонин, Н.К. Моделирование урожаев в системе точного земледелия / Н.К. Вахонин // Мелиорация. 2015. - № 1 (73). - С. 131-136.

12. Красовский, Г.И. Планирование эксперимента / Г.И. Красовский, Г.Ф. Филаретов. - Минск : Изд-во БГУ, 1982. $-303 \mathrm{c}$.

13. Лихацевич, А.П. Моделирование влияния регулируемых факторов среды на урожайность сельскохозяйственных культур / А. П. Лихацевич // Вес. Нац. акад. навук Беларусі. Сер. аграр. навук. - 2016. - №4. - С. 65-78.

14. Лихацевич, А.П. Анализ результатов агрономических опытов с использованием обобщенной математической модели / А. П. Лихацевич // Вес. Нац. акад. навук Беларусі. Сер. аграр. навук. - 2017. - № 2. - С. 68-81.

15. Аверьянов, С. Ф. Некоторые математические модели системы растение-среда / С. Ф. Аверьянов, В.В. Шабанов // Физическое и математическое моделирование в мелиорации : науч. тр. / ВАСХНИЛ ; под ред. С. Ф. Аверьянова. M., 1973. - C. 293-295.

16. Лихацевич, А.П. Влияние влаготеплообеспеченности на урожайность сельскохозяйственных культур (на примере многолетних трав и ярового тритикале) / А.П. Лихацевич, Е.И. Волкова // Мелиорация. - 2011. №2 (66). - C. 75-81.

\section{References}

1. Topazh A. G., Lekomtsev P. V., Pasynkov A. V., Pukhovskii A. V. Abnormal forms of the response "Fertilizer - productivity": field experiments and simulation analysis. Izvestiya Timiryazevskoi sel'skokhozyaistvennoi akademii = Izvestiya of Timiryazev Agricultural Academy, 2015, iss. 2, pp. 15-27 (in Russian).

2. Proshkin V. A. Simulation of the efficiency of mineral fertilizers on the basis of agrochemical soil properties. Agrokhimiya $=$ Agricultural Chemistry, 2012, no. 7, pp. 16-27 (in Russian).

3. Poluektov R. A. Dynamic models of agroecosystems. Leningrad, Gidrometeoizdat Publ., 1991. 312 p. (in Russian).

4. Valge A. M., Papushin E. A., Perekopskii A. N. Mathematical modeling of cropping power in perennial grasses. Vestnik Rossiiskoi akademii sel'skokhozyaistvennykh nauk [Bulletin of the Russian Academy of Agricultural Sciences], 2013, no. 5, pp. 8-10 (in Russian).

5. Semenenko N. N. Peat-bog soils of Polesie: transformation and ways of effective use. Minsk, Belaruskaya navuka Publ., 2015. 282 p. (in Russian).

6. Stepuro M. F. Application of methods of mathematical modelling in estimation of fertilizer systems and optimization of mineral nutrition of table beet. Ovoshchevodstvo: sbornik nauchnykh trudov [Vegetable growing: a collection of scientific works]. Minsk, 2012, iss. 20, pp. 245-254 (in Russian).

7. Stepuro M. F. Use of mathematical simulation methods for optimization of carrots fertilizing system. Kartofel' $i$ ovoshchi $=$ Potato and Vegetables, 2013, no. 1, pp. 19-21 (in Russian).

8. Shapovalov N. K., Soldat I. E. Mathematical modeling of the management of production process on sugar beet sowing. Dostizheniya nauki i tekhniki APK = Achievements of Science and Technology of AICis, 2013, no. 2, pp. 29-31 (in Russian).

9. Vakhonin N. K. Methodological principles of setting objectives for plant growing optimization. Melioratsiya pereuvlazhnennykh zemel' [Melioration of Wetlands], 2007, no. 2 (58), pp. $73-79$ (in Russian).

10. Vakhonin N. K. Conceptual bases of yield modeling in the decision-making system concerning water regime regulation. Melioratsiya [Land Reclamation], 2014, no. 2 (72), pp. 7-15 (in Russian).

11. Vakhonin N. K. Yield modeling in the system of precise farming. Melioratsiya [Land Reclamation], 2015, no. 1 (73), pp. 131-136 (in Russian).

12. Krasovskii G. I., Filaretov G. F. Planning an experiment. Minsk, Publishing house of the Belarusian State University, 1982. 303 p. (in Russian).

13. Likhatsevich A. P. The effect of controlled environmental factors on crop yield. Vestsi Natsyyanal'nai akademii navuk Belarusi. Seryya agrarnykh navuk = Proceedings of the National Academy of Sciences of Belarus. Agrarian series, 2016, no. 4, pp. 65-78 (in Russian).

14. Likhatsevich A. P. Generalized mathematical model for analyzing obtained results of agronomic experiments. Vestsi Natsyyanal'nai akademii navuk Belarusi. Seryya agrarnykh navuk = Proceedings of the National Academy of Sciences of Belarus. Agrarian series, 2017, no. 2, pp. 68-81 (in Russian).

15. Aver'yanov S. F., Shabanov V. V. Some mathematical models of the plant-environment system. Fizicheskoe $i$ matematicheskoe modelirovanie v melioratsii [Physical and mathematical modeling in land reclamation]. Moscow, 1973, pp. 293295 (in Russian).

16. Likhatsevich A. P., Volkova E. I. Influence of water and warmth provision on crop yields (on the example of perennial herbs and spring triticale). Melioratsiya [Land Reclamation], 2011, no. 2 (66), pp. 75-81 (in Russian). 


\section{Информацмя об авторе}

Лихацевич Анатолий Павлович - член-корреспондент, доктор технических наук, профессор, главный научный сотрудник, Институт мелиорации, Национальная академия наук Беларуси (ул. М. Богдановича, 153, Минск, 200040, Республика Беларусь). E-mail: niimel@mail.ru

\section{Information about the author}

Likhatsevich Anatoly P. - Corresponding Member, D.Sc. (Engineering), Professor. The Institute of Land Reclamation, the National Academy of Sciences of Belarus (153 M. Bogdanovicha Str., 220040 Minsk, Republic of Belarus).E-mail: niimel@mail.ru 